Research Article

\title{
Incisor Molar Hypomineralization and Quality of Life: A Population-Based Study with Brazilian Schoolchildren
}

\author{
Liege Helena Freitas Fernandes $\mathbb{D}^{1},{ }^{1}$ Isla Camila C. Laureano $\mathbb{D},,^{1}$ Lunna Farias $\left(\mathbb{D},{ }^{1}\right.$ \\ Natália M. Andrade, ${ }^{1}$ Franklin Delano Soares Forte $\mathbb{D}^{\mathbb{D}},{ }^{2}$ Catarina Ribeiro Barros Alencar $\mathbb{D}^{\mathbb{D}},{ }^{3}$ \\ and Alessandro Leite Cavalcanti $\mathbb{D}^{1}$ \\ ${ }^{1}$ Department of Dentistry, State University of Paraíba, Campina Grande, Paraíba, Brazil \\ ${ }^{2}$ Department of Clinical and Social Dentistry, Federal University of Paraíba, João Pessoa, Paraíba, Brazil \\ ${ }^{3}$ Academic Unit of Biological Sciences, Faculty of Dentistry, Federal University of Campina Grande, Patos, Paraíba, Brazil
}

Correspondence should be addressed to Alessandro Leite Cavalcanti; alessandrouepb@gmail.com

Received 9 November 2020; Revised 10 February 2021; Accepted 23 February 2021; Published 3 March 2021

Academic Editor: Stefano Corbella

Copyright (c) 2021 Liege Helena Freitas Fernandes et al. This is an open access article distributed under the Creative Commons Attribution License, which permits unrestricted use, distribution, and reproduction in any medium, provided the original work is properly cited.

\begin{abstract}
Aim. To assess the impact of incisor molar hypomineralization (MIH) on oral health-related quality of life (OHRQoL) according to the perception of students and their parents/caregivers. Materials and Methods. This is a cross-sectional population-based study with 463 Brazilian students aged 11-14 years. OHRQoL was measured using the Child Perceptions Questionnaire (B-CPQ $11-$ ${ }_{14}$ ISF: 16) applied to students and the short version of the Parental-Caregiver Perceptions Questionnaire (B-P-CPQ) applied to parents/caregivers. The diagnosis of MIH followed the European Academy of Paediatric Dentistry criteria modified in 2019. Caries experience (ICDAS II), malocclusion (DAI), and socioeconomic and demographic factors were assessed as confounding factors for impact on OHRQoL. Cluster analysis was carried out to dichotomize the negative impact into greater and lesser impact. The chi-square test and Poisson regression were performed $(p<0.05)$ to verify associations between quality of life and MIH, adjusted for confounding variables. Results. The prevalence of MIH was $10.8 \%$. Multivariate regression demonstrated that caries experience was the only oral disease that impacted OHRQoL according to students' self-perception in the functional limitation domain $(\mathrm{PR}=1.82 ; 95 \% \mathrm{CI}=1.20-2.77)$ and in the total questionnaire score $(\mathrm{PR}=1.59 ; 95 \% \mathrm{CI}=1.00-2.51)$. However, according to the perception of parents/caregivers, in addition to caries experience, which affected OHRQoL in the oral symptoms $(\mathrm{PR}=3.57 ; 95 \%$ $\mathrm{CI}=1.71-7.414)$ and emotional well-being domains $(\mathrm{PR}=1.71 ; 95 \% \mathrm{CI}=1.08-2.69)$, as well as in the total B-P-CPQ score $(\mathrm{PR}=1.67 ; 95 \% \mathrm{CI}=1.01-2.76)$, malocclusion also affected $\mathrm{OHRQoL}$ in the social well-being domain $(\mathrm{PR}=1.50 ; 95 \%$ $\mathrm{CI}=1.07-2.10)$ and in the total questionnaire score $(\mathrm{PR}=1.54 ; 95 \% \mathrm{CI}=1.11-2.15)$. Conclusion. According to students and their parents/caregivers' perception, incisor molar hypomineralization did not influence OHRQoL of the studied sample.
\end{abstract}

\section{Introduction}

Quality of life is defined as the perception of well-being and personal and subjective manifestation of good feeling within the sociocultural context in which one lives [1]. During childhood, oral changes can affect the quality of children's systemic health [2]. Additionally, the oral condition also influences the quality of life, which can greatly impact psychological and social aspects [1]. The negative effects of poor dental appearance are irrefutable, also affecting social interaction [3].
The literature reports that enamel defects affect the quality of life of individuals with this condition since enamel defects can modify both aesthetics and the function of teeth [1]. Among these changes, incisor molar hypomineralization (MIH) has stood out and received increasing attention from dentists in several countries [4].

MIH is a qualitative enamel defect of systemic nature affecting one or more permanent first molars, with or without incisor involvement [5]. Clinically, it can vary from the lightest forms, characterized by well-marked opacities to posterior 
ruptures [5], since in MIH-affected teeth, the enamel is porous and susceptible to fracture [6].

Teeth with MIH generally present greater sensitivity [7], greater tendency to develop carious lesions [8], difficulty in obtaining the anesthetic effect $[6,9]$, and require multiple clinical interventions due to the difficulty in obtaining satisfactory adhesion of restorative materials to the dental substrate [9, 10], in addition to longer clinical care [10]. Therefore, $\mathrm{MIH}$ is associated with a series of oral morbidities, such as tooth hypersensitivity and poor dental aesthetics, affecting the quality of life [11].

The association between the presence of $\mathrm{MIH}$ and quality of life has been previously reported in some studies both in Brazil [12, 13] and in other countries, such as Colombia [1] and Mexico [14]. However, given the existence of particularities in the occurrence and comorbidities associated with $\mathrm{MIH}[5,8,15,16]$, this relationship needs to be investigated in more detail, considering its cultural and socioeconomic diversities [17].

Thus, in view of the scarcity of literature data, this study aimed to assess the impact of the presence and severity of MIH on the OHRQoL of Brazilian schoolchildren aged 11-14 years.

\section{Materials and Methods}

2.1. Study Design and Location. This is a cross-sectional study conducted in Campina Grande, Paraíba, Brazil. The city has an estimated population of 407,472 inhabitants, Human Development Index (HDI) of 0.72, and Gini coefficient of 0.58 [18]. This study followed recommendations established by the Strengthening the Reporting of Observational Studies in Epidemiology (STROBE) [19].

2.2. Population and Sample Calculation. Participants were selected from a total population of 53,596 schoolchildren [18], regularly enrolled in elementary schools in the municipality of Campina Grande, Brazil. Sampling was of probabilistic type by clusters, and for sample calculation, the formula of infinite population was used: $n=z^{2} \times P(1-P) /$ $\mathrm{FE}^{2}$, where $n$ represents the sample size; $z$ represents the confidence level (95\%), standard deviation (1.96); $P$ represents the expected prevalence of the phenomenon to be investigated, 18.4\% [12]; FE represents the predicted sample error factor (5\%). A correction factor of 1.8 was used, as well as an increment of $10 \%$ to compensate for possible losses, with the final sample estimated at 463 students. Two public schools were drawn in each of the six selected urban Health Districts (HD), totaling 12 institutions.

2.3. Inclusion and Exclusion Criteria. All 11-14-year-old schoolchildren who had all first permanent molars fully erupted were included. Schoolchildren with fixed orthodontic appliance at the time of evaluation were excluded [12-14], as well as those with special needs (according to parents' reports) who did not cooperate with a clinical examination or were unable to answer the questionnaires.
2.4. Calibration. Theoretical and practical calibrations of the three examiners were performed by gold standard researchers with previous experiences in epidemiological investigations to diagnose $\mathrm{MIH}[20]$, dental caries [20,21], and malocclusion. For MIH, Cohen's Kappa coefficient was 0.61-0.72 for interexaminer calibration and $0.67-0.83$ for intraexaminer calibration.

For dental caries was used the International Caries Detection and Assessment System (ICDAS II) index, examiners took theoretical training online at https://www. iccms-web.com/, and regarding discussions about clinical diagnosis [22], the e practical stage was held in a public school. The interexaminer Kappa correlation values found ranged from 0.80 to 0.90 and intraexaminers values from 0.71 to 0.75 .

For malocclusion, criteria proposed by Jenny and Cons [23] and the Brazilian Ministry of Health [24] were used. Cohen's Kappa coefficient was $0.76-0.89$ for interexaminer calibration and 0.82-0.94 for intraexaminer calibration.

2.5. Data Collection. Data collection was performed in two stages between September and December 2019. The first stage was performed by parents/caregivers. They signed the consent form and answered the socioeconomic questionnaire and the Brazilian short form of the Parental-Caregivers' Perceptions Questionnaire (P-CPQ) [25].

The social and demographic questionnaires contained questions concerning parents/caregivers and students such as sex, age, family income (categorized based on the Brazilian monthly minimum wage amount equivalent to US\$ 264.00), parents/caregivers' schooling in years of formal study ( $\leq 8$ years of study/ $>8$ years of study), and family structure (nuclear family structure when the child lives with parents who were married or in a stable union and nonnuclear structure when the child lives with only one single, divorced, or widowed parent), in addition to data on the use of dental services.

The reduced form of the B-P-CPQ questionnaire has 13 questions divided into three domains: oral symptoms, functional limitations, and well-being, referring to the last three months. The answer options range from zero to four points (between never and every day or almost every day). "I do not know" responses are allowed and scored 0 . The total score ranged from 0 to 52 . The higher the score, the higher the impact of oral condition on quality of life [25].

The second stage was performed by the schoolchildren whose parents/caregivers consented to study participation. They were directed to answer the self-reported 16-item Child Perception Questionnaire $\left(\mathrm{CPQ}_{11-14} \mathrm{ISF}: 16\right)$ [26] and were clinically assessed.

The Brazilian version of the questionnaire $\mathrm{CPQ}_{11-14} \mathrm{ISF}$ : 16 consisted of 16 items divided into four areas: oral symptom, functional limitation, emotional well-being, and social well-being. Each item addressed the frequency of events in the previous three months. Response options ranged from zero to four points, indicating the occurrence frequency (between "never" and "every day or almost every day"). The total score ranged from 0 to 64 , and higher scores 
denoted a more negative impact of oral conditions on OHRQoL [26].

Before the clinical examination, children were instructed on oral hygiene procedures and received fluoridated toothpaste and toothbrush by means of which their teeth were cleaned by supervised brushing.

Clinical examinations took place in a reserved place in the school, under natural light, with the help of headlamps (JWS Lanternas, São Paulo, SP, Brasil). Researchers used all personal protective equipment, mouth mirrors (Golgran Indústria e Comércio de Instrumental Odontológico, São Caetano do Sul, SP, Brazil), and WHO probes (Trinity Indústria e Comércio Ltda., São Paulo, SP, Brazil) and sterilized in autoclave gauze (Gnatus Equipamentos MédicoOdontológicas Ltda., Barretos, SP, Brasil) to dry teeth, which is in line with infection control standards [27].

The presence of MIH was recorded when at least one first permanent molar was affected by demarcated opacities, ranging from white-cream-yellow-brown, due to posteruptive enamel fractures, by atypical restorations/atypical carious lesions, or when there was an absence of permanent molars due to $\mathrm{MIH}$-all these clinical features with or without the involvement of incisors [20]. MIH severity was classified as mild, only color changes-cream, white, yellow, orange, or brown-and severe-fracture and/or atypical restoration/atypical caries/loss due to MIH [21]. MIH severity was defined by the most severe defect observed in first permanent molars and/or permanent incisors [28].

Schoolchildren were also evaluated to determine their caries experience, malocclusion, and presence of other enamel defects, as they are considered confounding variables [12]. Children were evaluated to determine their dental caries experience according to the International Caries Detection and Assessment System II (ICDAS II) [29]. Dental caries was considered present for ICDAS code $>0$. Malocclusion was assessed using the Dental Aesthetic Index (DAI). DAI components are divided into three groups: tooth, space, and occlusion and placed in an equation, which classified as absence (DAI $\leq 25)$ and presence (DAI >25) of malocclusion [23].

Differential MIH diagnosis was performed with diffuse opacities (fluorosis), with white spots of dental caries, imperfect amelogenesis, enamel hypoplasia, and hypomineralization defects other than $\mathrm{MIH}$ [20].

2.6. Statistical Analysis. Data were analyzed using IBM SPSS Statistics (IBM SPSS Statistics for Windows, Version 22.0. Armonk, NY: IBM Corp). The internal consistency of the OHRQoL questionnaire was examined by computing Cronbach's alpha coefficients. In order to dichotomize the total score and the domains of the $\mathrm{B}-\mathrm{CPQ}_{11-14} \mathrm{ISF}: 16$ and $\mathrm{B}-\mathrm{P}-\mathrm{CPQ}$ instruments in a greater and lesser negative impact on OHRQoL, $k$-means cluster analysis was performed. Cluster analysis assesses the pattern of responses for each item separately and for the formation of clusters. It considers the correlation between the responses to the instrument and can be valid because there is no cutoff pattern for the sum of questions of $\mathrm{B}-\mathrm{CPQ}_{11-14} \mathrm{ISF}: 16$ and $\mathrm{B}-\mathrm{P}-\mathrm{CPQ}$ instruments for the total score and their domains.
A descriptive statistical analysis was performed, and the Kolmogorov-Smirnov test was used to verify the normality of quantitative variables. The chi-square test was used to verify the association between the negative impact on OHRQoL with MIH and confounding variables (caries experience, malocclusion, other enamel defects, and socioeconomic factors). In multivariate analysis, Poisson regression was performed with a robust variance; all variables with $p<0.2$ in the bivariate analysis were included in the adjusted multivariate analysis. Prevalence ratios (PR) with the respective $95 \%$ confidence intervals (95\% CI) were calculated for associations. Variable "MIH in molars" was removed from the adjusted analysis of the B-P-CPQ questionnaire for presenting collinearity with variable "Presence of MIH.” A significance level of 5\% was adopted.

2.7. Ethical Aspects. This study was approved by the local institutional ethics committee under opinion No. 3.155.847. All study procedures were conducted in accordance with Resolution 466/12 of the Brazilian National Health Council and the Declaration of Helsinki and its subsequent amendments.

\section{Results}

A total of 590 children were invited, of whom 463 agreed to participate in the study. The prevalence of MIH was $10.8 \%$ $(n=50)$. Regarding severity, $22(44.0 \%)$ students had a mild degree and $28(56.0 \%)$ had a severe degree. A total of $80.1 \%$ of the sample had caries experience, $48.4 \%$ had malocclusion, and with respect to other enamel defects, $10.6 \%$ was diagnosed with fluorosis, $1.1 \%$ with hypoplasia, $0.2 \%$ had imperfect amelogenesis, and $4.5 \%$ had other types of hypomineralization (Table 1).

Tables 2 and 3 show the bivariate analysis between the negative impact of domains and the total score of OHRQoL instruments and independent variables. It was observed that according to the self-perception of students, the presence of $\mathrm{MIH}$, regardless of severity degree, was not associated with OHRQoL. Regarding parents/caregivers' perception, schoolchildren with MIH were associated with a negative impact on OHRQoL in the emotional well-being domain ( $p=0.046$ ). In addition, the presence of MIH in molars was also associated with the emotional well-being domain $(p=0.046)$.

Tables 4 and 5 show the crude multivariate models, and Tables 6 and 7 show the final multivariate models of negative impacts of independent variables on self-perceived OHRQoL and OHRQoL perceived by parents, distributed by domains and total scores of the B-CPQ ${ }_{11-14}$ ISF: 16 and B-P-CPQ instruments. According to the self-perception of students, the only oral disease that had influence on OHRQoL was dental caries experience, which had $82.8 \%$ greater impact rate in the functional limitation domain $\left(\mathrm{PR}_{\mathrm{adjusted}}=1.82 ; 95 \% \mathrm{CI}=1.20-2.77\right)$ and $59 \%$ in the total B-CPQ ${ }_{11-14} \mathrm{ISF}: 16$ score $\left(\mathrm{PR}_{\text {adjusted }}=1.59 ; 95 \%\right.$ $\mathrm{CI}=1.00-2.51)$. In addition, females perceived greater impact on OHRQoL in the functional limitation domain $\left(\mathrm{PR}_{\text {adjusted }}=1.52 ; 95 \% \mathrm{CI}=1.14-2.02\right)$, and the lower parental 
TABle 1: Sample characterization regarding sociodemographic, economic, and clinical factors.

\begin{tabular}{|c|c|}
\hline Variable & $n(\%)$ \\
\hline \multicolumn{2}{|l|}{ Sex } \\
\hline Female & $293(63.3)$ \\
\hline Male & $170(36.7)$ \\
\hline \multicolumn{2}{|l|}{ Age } \\
\hline 11 & $141(30.5)$ \\
\hline 12 & $168(36.3)$ \\
\hline 13 & $101(21.8)$ \\
\hline 14 & $53(11.4)$ \\
\hline \multicolumn{2}{|c|}{ Family income in minimum wages $(\mathrm{MW})^{1}$} \\
\hline$\leq 1 \mathrm{MW}$ & $350(83.7)$ \\
\hline$>1 \mathrm{MW}$ & $68(16.3)$ \\
\hline \multicolumn{2}{|c|}{ Parents/caregivers'schooling } \\
\hline$\leq 8$ years of study & $276(60.7)$ \\
\hline$>8$ years of study & $179(39.3)$ \\
\hline \multicolumn{2}{|l|}{ Family structure } \\
\hline Nonnuclear & $229(49.5)$ \\
\hline Nuclear & $234(50.5)$ \\
\hline \multicolumn{2}{|c|}{ Visited the dentist once in life } \\
\hline Yes & $356(76.9)$ \\
\hline No & $107(23.1)$ \\
\hline \multicolumn{2}{|l|}{$\mathrm{MIH}$} \\
\hline Present & $50(10.8)$ \\
\hline Absent & $413(89.2)$ \\
\hline \multicolumn{2}{|l|}{ MIH on incisors } \\
\hline Present & $16(3.5)$ \\
\hline Absent & $447(96.5)$ \\
\hline \multicolumn{2}{|l|}{ MIH on molars } \\
\hline Present & $50(10.8)$ \\
\hline Absent & $413(89.2)$ \\
\hline \multicolumn{2}{|l|}{ MIH severity } \\
\hline Mild & $22(44.0)$ \\
\hline Severe & $28(56.0)$ \\
\hline \multicolumn{2}{|c|}{ Dental caries experience } \\
\hline Yes & $371(80.1)$ \\
\hline No & $92(19.9)$ \\
\hline \multicolumn{2}{|l|}{ Malocclusion } \\
\hline Present & $224(48.4)$ \\
\hline Absent & $239(51.6)$ \\
\hline \multicolumn{2}{|l|}{ Dental fluorosis } \\
\hline Present & $49(10.6)$ \\
\hline Absent & $414(89.4)$ \\
\hline \multicolumn{2}{|l|}{ Hypoplasia $^{2}$} \\
\hline Present & $5(1.1)$ \\
\hline Absent & $458(98.9)$ \\
\hline \multicolumn{2}{|c|}{ Amelogenesis imperfecta $^{2}$} \\
\hline Present & $1(0.2)$ \\
\hline Absent & $462(99.8)$ \\
\hline \multicolumn{2}{|c|}{ Hypomineralization other than MIH } \\
\hline Present & $21(4.5)$ \\
\hline Absent & $442(95.5)$ \\
\hline
\end{tabular}

${ }^{1}$ Value of the Brazilian minimum wage in force at the time of the research was equivalent to Rs. 99,800 (US\$264.00). ${ }^{2}$ Due to the very low $N$, the variable was not included in the regression analysis.

schooling had impact on emotional well-being $\left(\mathrm{PR}_{\text {adjusted }}=1.59 ; 95 \% \mathrm{CI}=1.17-2.15\right)$ and social well-being domains $\left(\mathrm{PR}_{\text {adjusted }}=1.45 ; 95 \% \mathrm{CI}=1.01-2.07\right)$ (Table 6).
According to the perception of parents/caregivers, students with caries experience had $57.5 \%$ greater impact rate in the oral symptoms domain $\left(\mathrm{PR}_{\text {adjusted }}=3.57 ; \quad 95 \%\right.$ $\mathrm{CI}=1.71-7.414), 71.1 \%$ in emotional well-being domain $\left(\mathrm{PR}_{\text {adjusted }}=1.71 ; 95 \% \mathrm{CI}=1.08-2.69\right)$, and $67.8 \%$ in the total B-P-CPQ score $\left(\mathrm{PR}_{\text {adjusted }}=1.67 ; 95 \% \mathrm{CI}=1.01-2.76\right)$. Additionally, malocclusion also negatively influenced $\mathrm{OHRQOL}$ in the social well-being domain $\left(\mathrm{PR}_{\text {adjusted }}=1.50 ; 95 \%\right.$ $\mathrm{CI}=1.07-2.10)$ and in the total questionnaire score $\left(\mathrm{PR}_{\text {adjusted }}=1.54 ; 95 \% \mathrm{CI}=1.11-2.15\right)$. Female gender, older age, lower family income, and never having visited the dentist also had negative impact on quality of life (Table 7).

\section{Discussion}

MIH is an enamel defect that has been increasingly studied by the dental community [4]. However, literature is still scarce concerning the impact of MIH on patients' oral health quality. Thus, studies of this nature are necessary since they contribute to the planning of oral health promotion programs that are socially appropriate for the target population [17].

Although there is convincing evidence that children with enamel defects experience a variety of psychosocial impacts [3], which can affect their quality of life and cause behavioral problems [6], in this study, the presence of $\mathrm{MIH}$ or other enamel defects did not demonstrate impact on OHRQoL from the self-perception of students or the perception of their parents/caregivers. In other studies conducted with Brazilian children and adolescents, MIH had a negative impact on OHRQoL $[12,13]$. It is believed that the divergence among studies may have occurred due to the cultural differences of the Brazilian population since Brazil is a country with continental dimensions with different cultures depending on the region $[30,31]$. When considering culturally diverse individuals, it is known that in addition to their different physical, emotional, or social needs, their oral health perceptions may also differ [32].

In this study, caries experience had a higher prevalence when compared to MIH. The occurrence of this disease has been decreasing in recent decades, causing many Western populations to be classified as having a low caries rate; however, its control remains a challenge for many population groups [33]. The literature has shown that caries' presence negatively affects the OHRQoL of patients $[2,34,35]$, which was also observed in this study. This negative impact possibly masked the influence of MIH on the OHRQoL of the population under study.

Dental caries cause functional changes, such as chewing and speaking problems, difficulty sleeping and irritability, also influencing other factors, such as school absenteeism [2]. These aspects may explain the impact of this condition on the OHRQoL of students in this study, both in their selfperception and in the perception of their parents/caregivers, thus evidencing the harmful effect of caries on the oral health of students [34].

Malocclusion had a negative impact on OHRQoL from the perception of parents/caregivers. This finding is in line with results found in the literature $[12,36]$, which was expected considering that, in this age group, corresponding to 


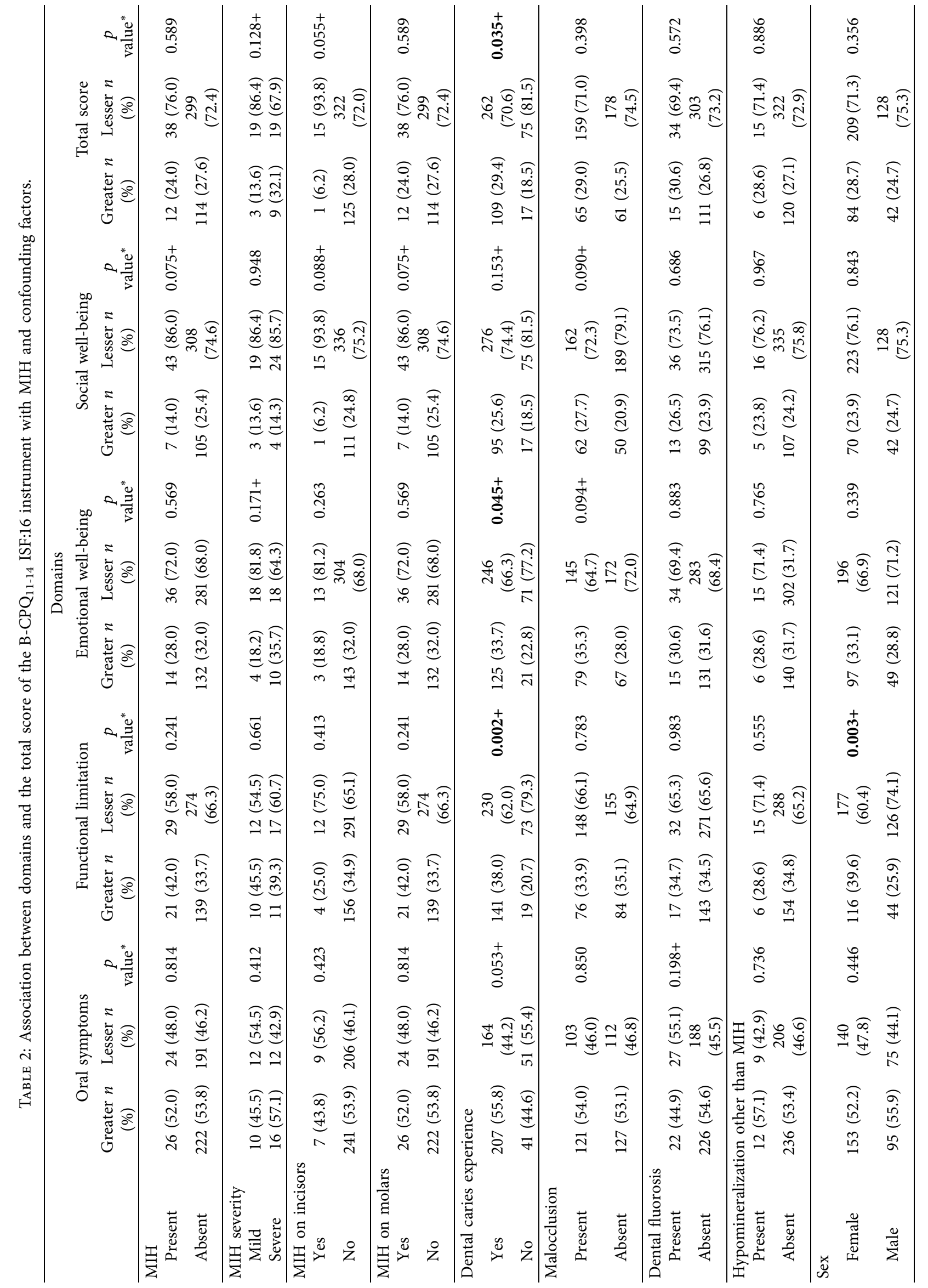




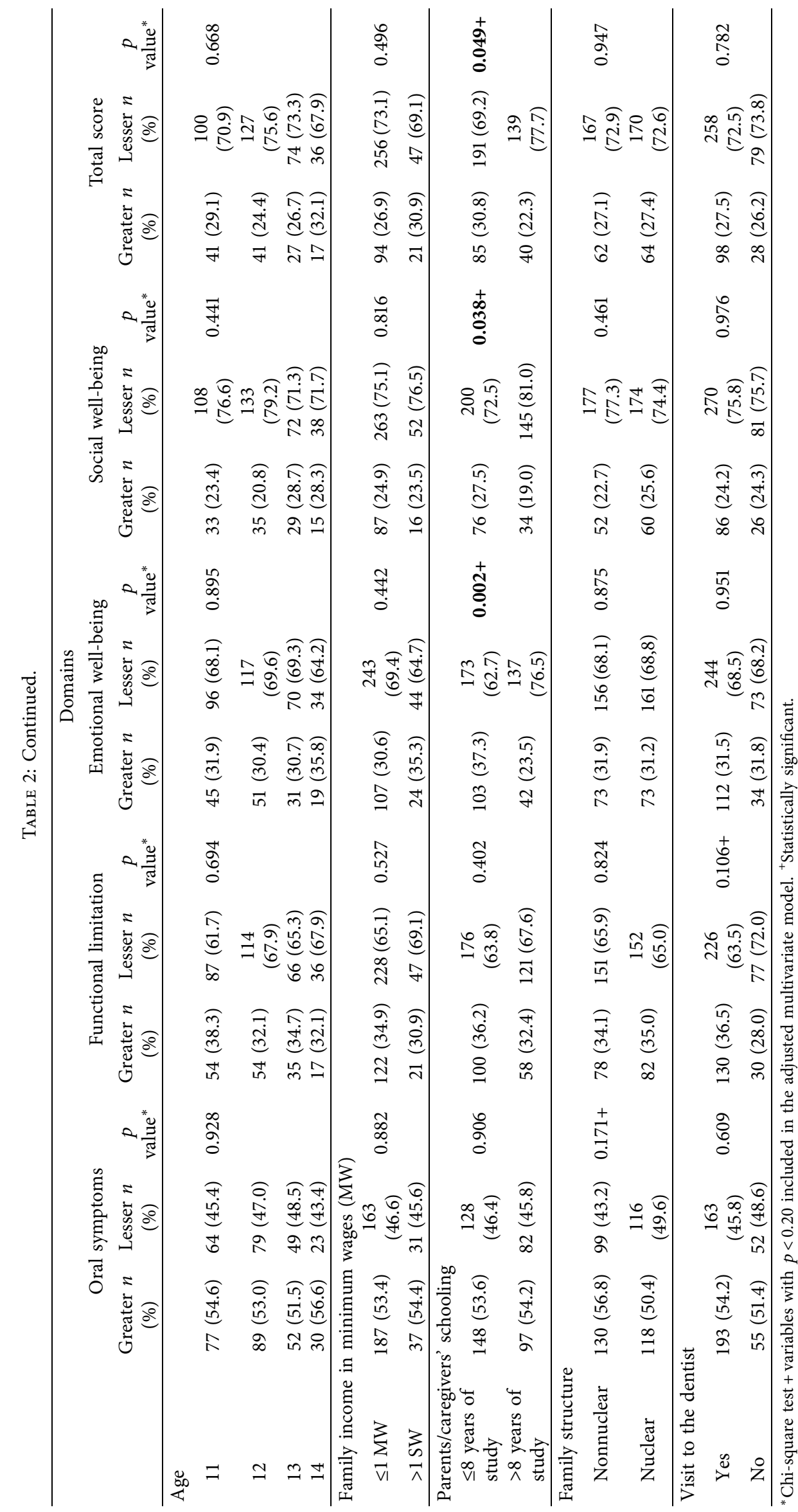




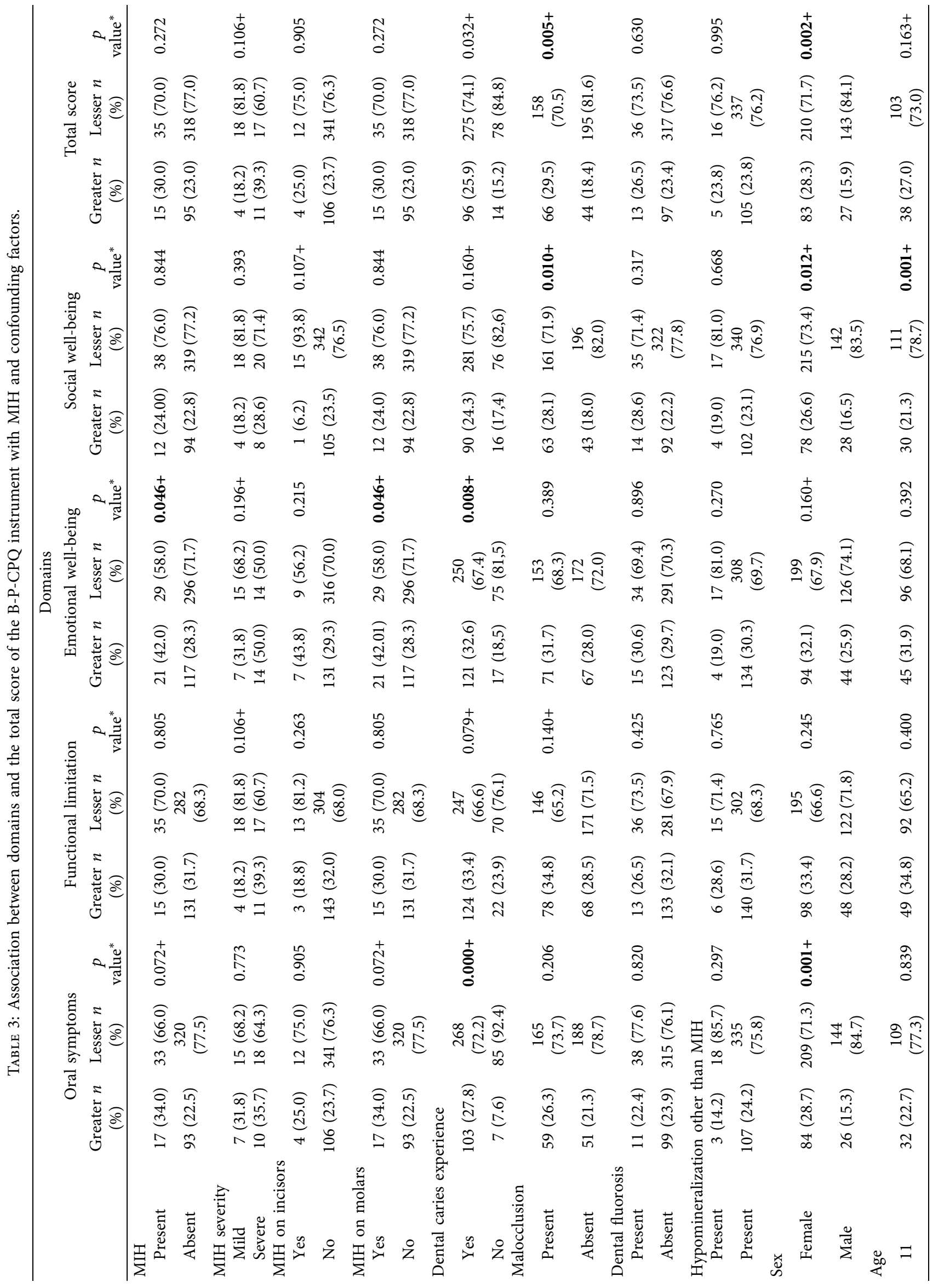




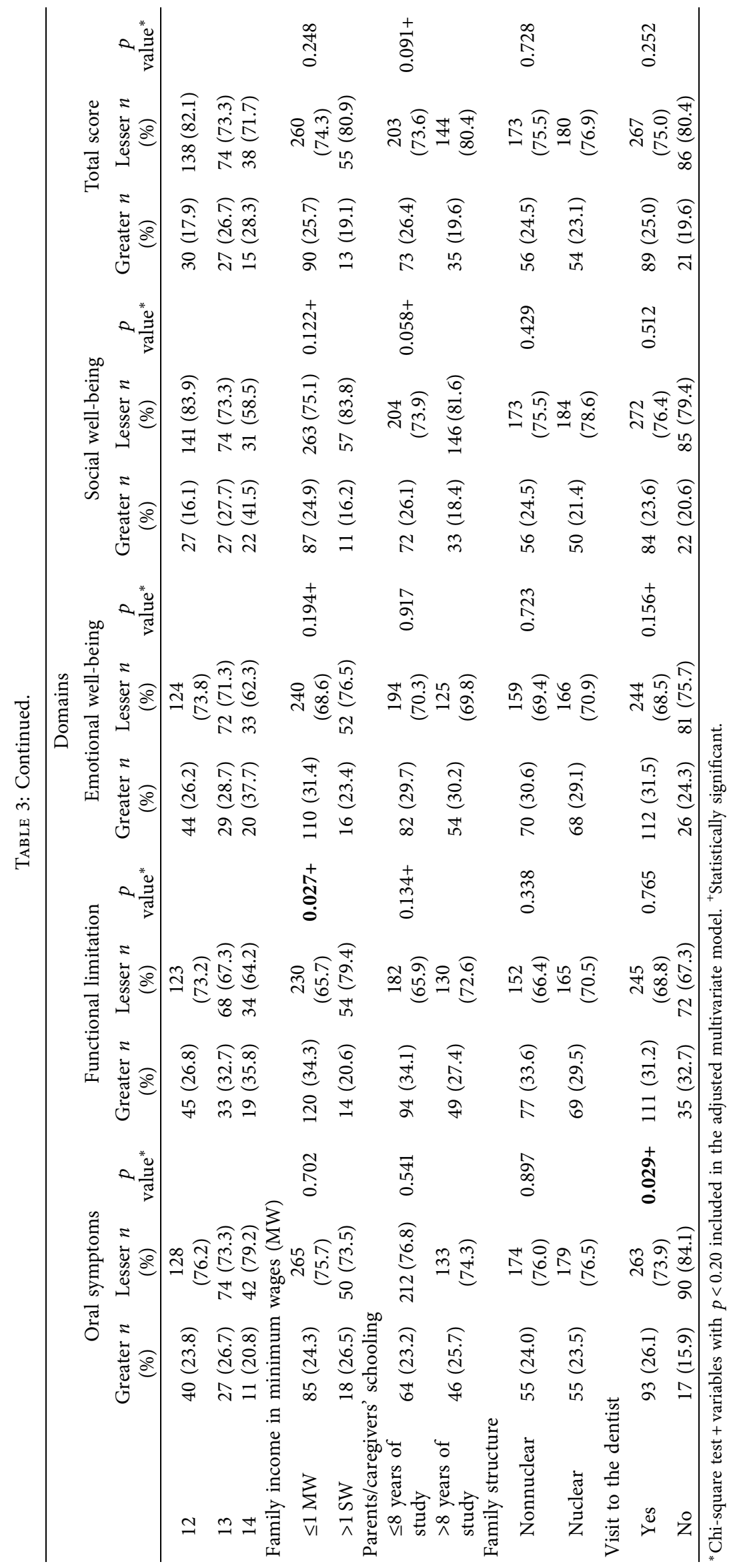




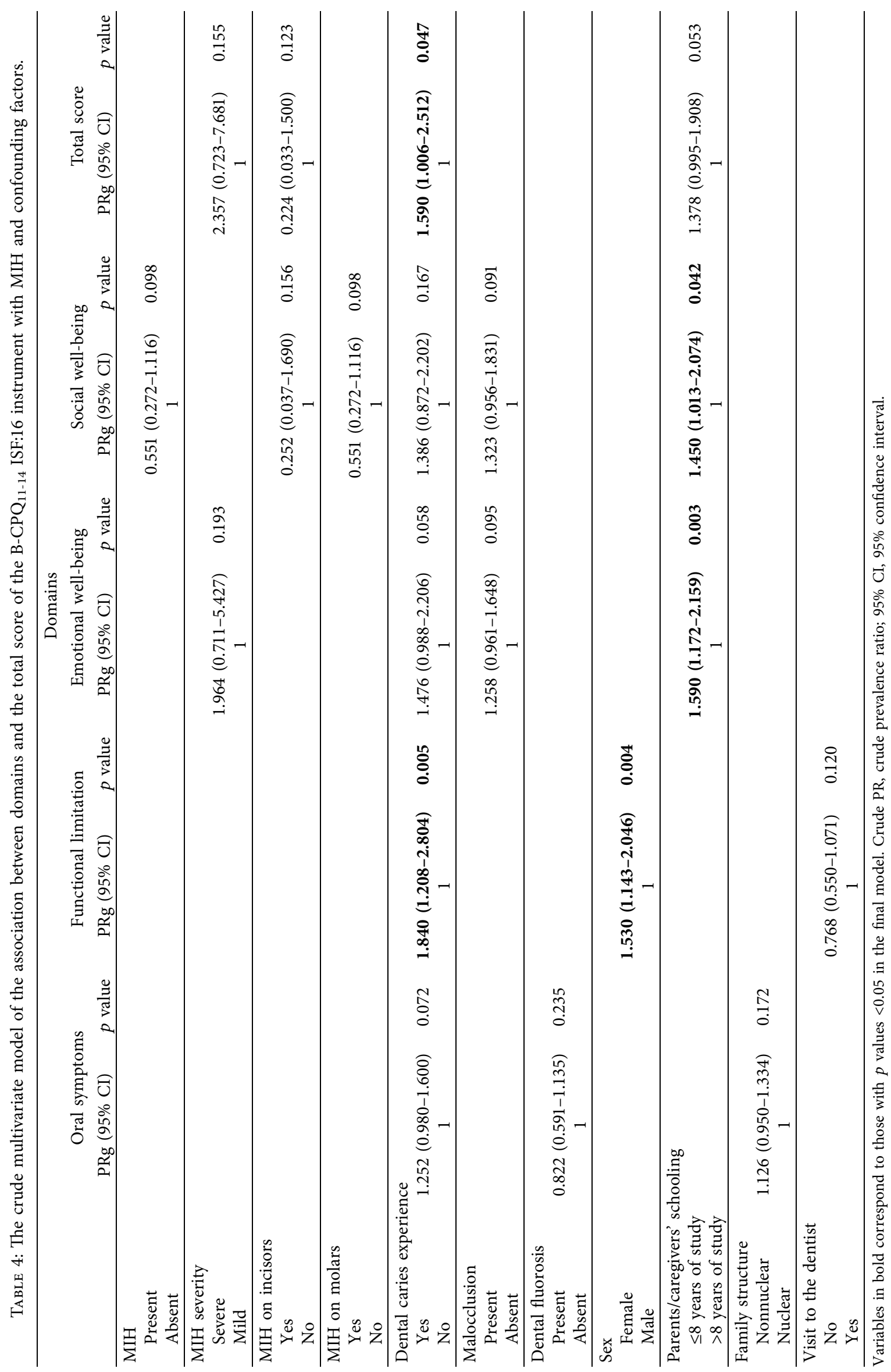




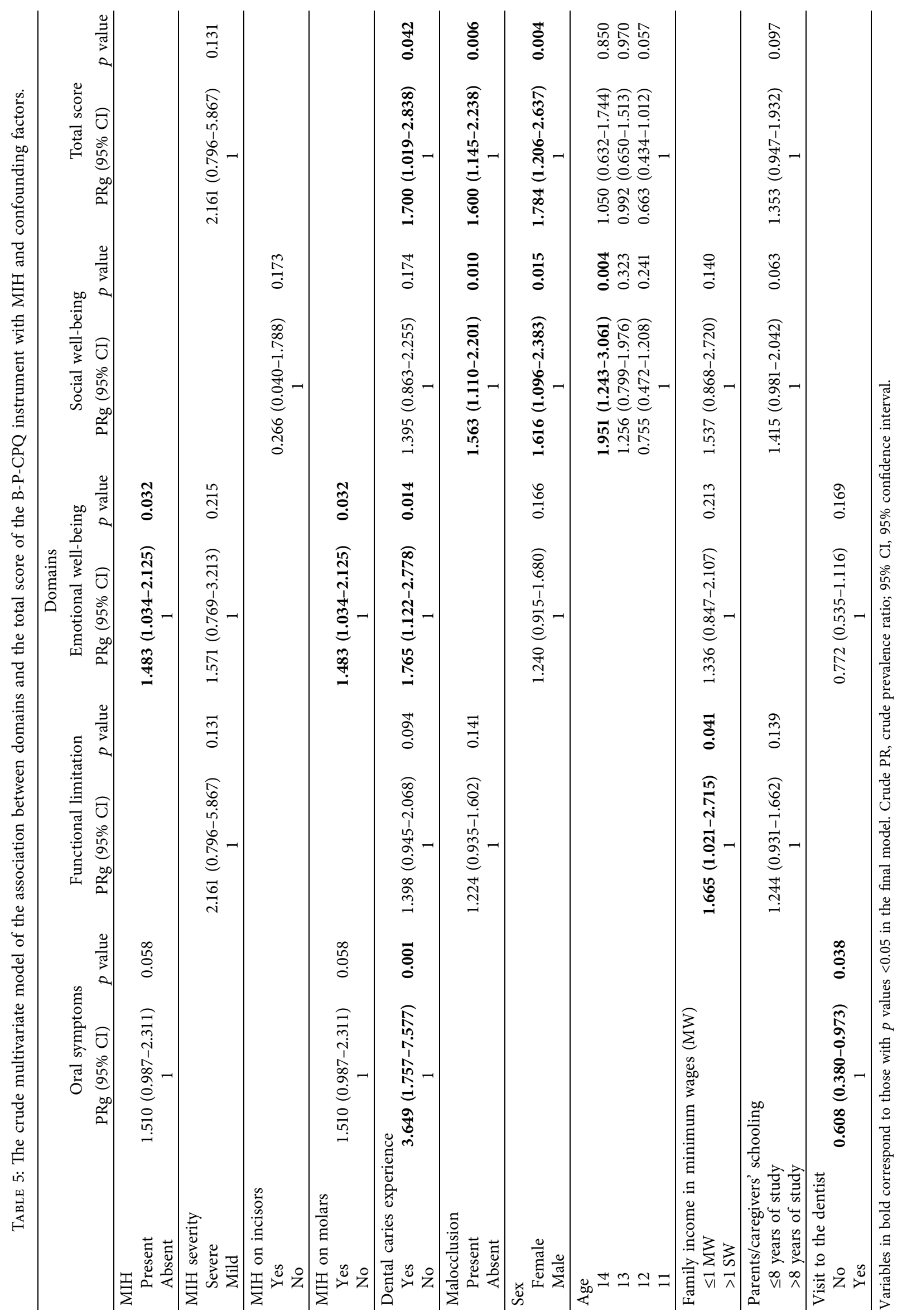




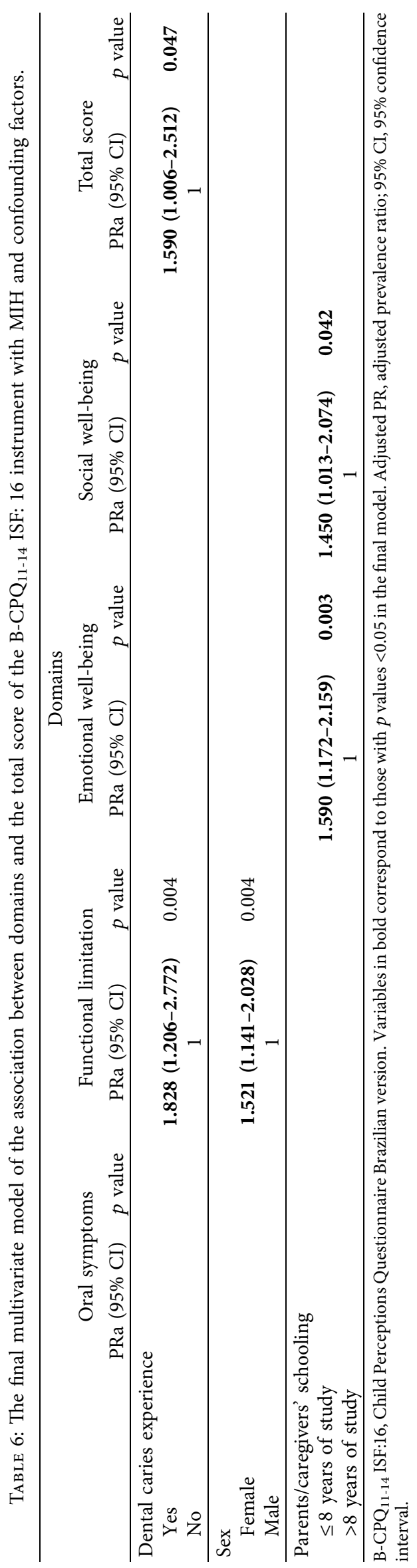




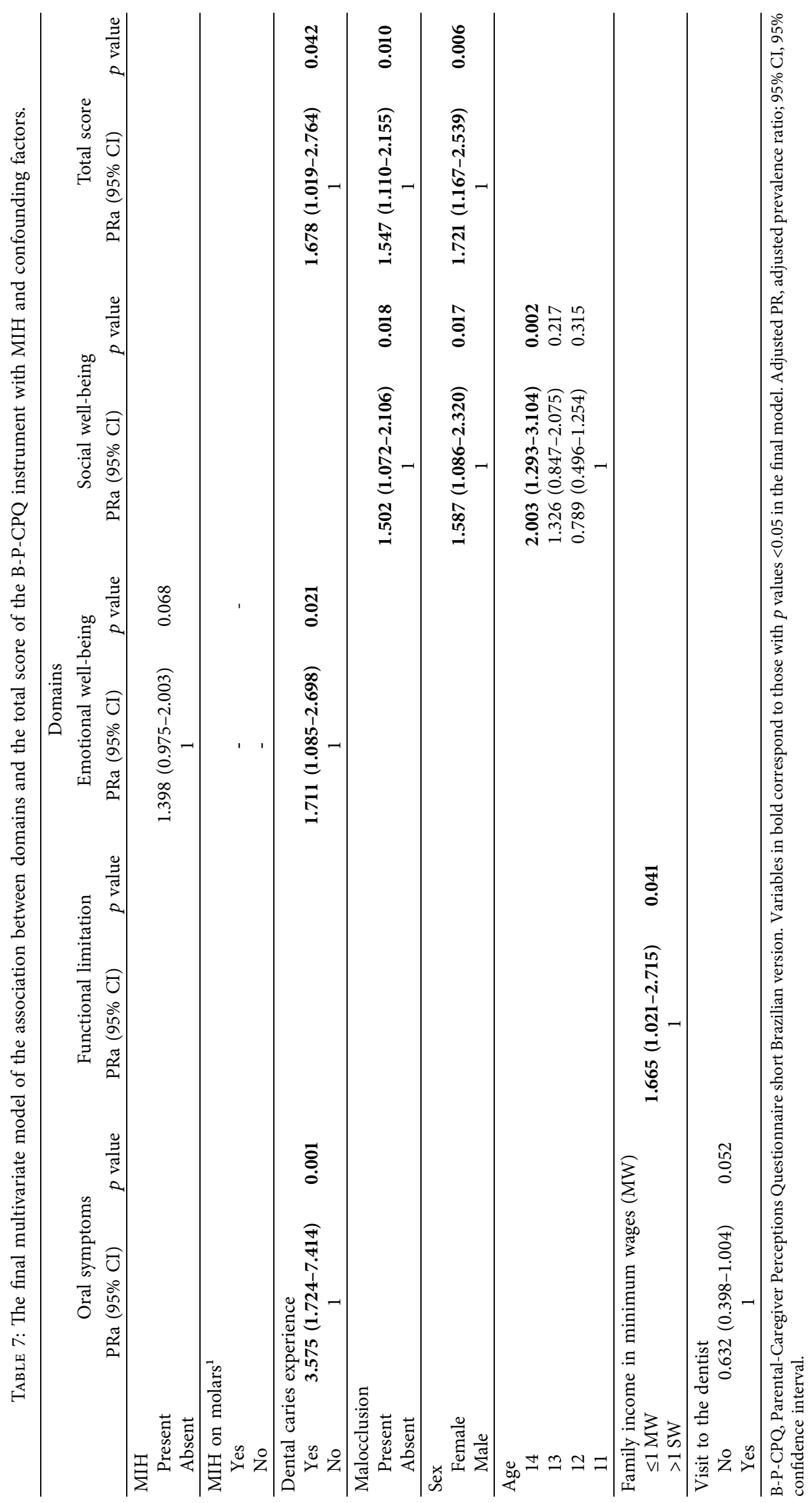


the beginning of adolescence, social life becomes more intense and appearance tends to become more important [36].

In the present study, female students showed a higher prevalence of impact on OHRQoL in the functional limitation domain of $\mathrm{CPQ}_{11-14}$ ISF:16 and the social well-being and total B-P-CPQ score from the perception of parents/ caregivers. This finding is similar to that reported in other studies [12-14]. Women are more concerned than men about oral health perception [37].

Oral diseases are cumulative and tend to worsen with increasing age [2], justifying the relationship between older ages and greater impact on the social well-being domain of OHRQoL from the perception of parents/ caregivers. Thus, the diagnosis and treatment of oral changes should occur as early as possible, reducing impacts on students' quality of life [2].

Concerning family income, the reduced availability of access to oral health services is a common reality in populations with low levels of financial resources [14]. Since Brazil is a country with great social disparities, this fact may explain the association between lower family income and a negative impact on the functional limitation of B-P-CPQ on the quality of life of students. This relationship has also been observed in other studies $[12,13,34]$.

The lower the schooling, the greater the chances of presenting inadequate oral health $[37,38]$. This statement may clarify the association between low schooling and impact on the emotional and social well-being domains of the OHRQoL self-perception questionnaire found in this study. Schooling may also reflect knowledge about the importance and maintenance of healthy oral habits, as well as being strongly associated with oral self-care [37, 39].

The cross-sectional design is among the limitations of this study, which analyzes data related to the perceptions of a specific moment [12], not allowing causal inferences. However, the population representativeness through sample calculation, high inter-examiner reliability, the conduction of a pilot study, and the use of validated questionnaires with a high response rate can be highlighted as strengths, aspects that reinforce the study validity.

For the development of public oral health policies from the perspective of a broad and appropriate health concept focused on improving quality of life, it is essential to understand the particularities of a given population [32]. Thus, the relevance of studies on the perception of OHRQoL in this planning is emphasized, as these strategies must be planned, taking into account the opinion of students and their parents/caregivers.

\section{Conclusion}

MIH had no impact on the OHRQoL of schoolchildren aged 11-14 years from the self-perception of schoolchildren or their parents/caregivers.

\section{Data Availability}

The data used to support the findings of this study are included within the article.

\section{Conflicts of Interest}

The authors declare that they have no conflicts of interest.

\section{Acknowledgments}

The authors like to acknowledge the Colgate Company for the donation of oral hygiene kits, Coordination for Improvement of Higher Education Personnel (CAPES) (Financing Code 001), National Council for Scientific and Technological Development (CNPq), Research Productivity Scholarship (302850/2016-3), and the State of Paraíba Research Support Foundation (FAPESQ/PB) (Concession Term 021/2018, Protocol 005/2018-SEIRHMACT/FAPESQ/ PB), Brazil.

\section{References}

[1] L. M. Velandia, L. V. Álvarez, L. P. Mejía, and M. J. Rodríguez, "Oral health-related quality of life in Colombian children with molar-incisor hypomineralization," Acta odontológica Latinoamericana, vol. 31, pp. 38-44, 2018.

[2] P. Corrêa-Faria, S. Paixão-Gonçalves, S. M. Paiva et al., "Dental caries, but not malocclusion or developmental defects, negatively impacts preschoolers' quality of life," International Journal of Paediatric Dentistry, vol. 26, no. 3, pp. 211-219, 2016.

[3] N. Hasmun, J. Lawson, M. Vettore, C. Elcock, H. Zaitoun, and H. Rodd, "Change in oral health-related quality of life following minimally invasive aesthetic treatment for children with molar incisor hypomineralisation: a prospective study," Dentistry Journal, vol. 6, no. 4, pp. 61-72, 2018.

[4] J. Fütterer, M. Ebel, K. Bekes, C. Klode, and C. Hirsch, "Influence of customized therapy for molar incisor hypomineralization on children's oral hygiene and quality of life," Clinical and Experimental Dental Research, vol. 6, no. 1, pp. 33-43, 2020.

[5] A. Ghanim, M. Elfrink, K. Weerheijm, R. Mariño, and D. Manton, "A practical method for use in epidemiological studies on enamel hypomineralisation," European Archives of Paediatric Dentistry, vol. 16, no. 3, pp. 235-246, 2015.

[6] I. Kosma, A. Kevrekidou, V. Boka, K. Arapostathis, and N. Kotsanos, "Molar incisor hypomineralisation (MIH): correlation with dental caries and dental fear," European Archives of Paediatric Dentistry, vol. 17, no. 2, pp. 123-129, 2016.

[7] C. M. B. Fragelli, J. F. d. Souza, F. Jeremias, R. d. C. L. Cordeiro, and L. Santos-Pinto, "Molar incisor hypomineralization (MIH): conservative treatment management to restore affected teeth," Brazilian Oral Research, vol. 29, no. 1, pp. 1-7, 2015.

[8] N. B. Dantas-Neta, M. Soares Figueiredo, C. C. B. Lima et al., "Factors associated with molar-incisor hypomineralisation in schoolchildren aged 8-10 years: a case-control study," International Journal of Paediatric Dentistry, vol. 28, no. 6, pp. 570-577, 2018.

[9] P. M. Schneider and M. Silva, "Endemic molar incisor hypomineralization: a pandemic problem that requires monitoring by the entire health care community," Current Osteoporosis Reports, vol. 16, no. 3, pp. 283-288, 2018.

[10] M. O. Folayan, T. A. Oyedele, and E. Oziegbe, "Time expended on managing molar incisor hypomineralization in a pediatric dental clinic in Nigeria," Brazilian Oral Research, vol. 32, p. e79, 2018. 
[11] T. A. Oyedele, M. O. Folayan, C. A. Adekoya-Sofowora, and E. O. Oziegbe, "Co-morbidities associated with molar-incisor hypomineralisation in 8 to 16 year old pupils in Ile-Ife, Nigeria," BMC Oral Health, vol. 13, pp. 15-37, 2015.

[12] N. B. Dantas-Neta, L. d. F. A. d. D. Moura, P. F. Cruz et al., "Impact of molar-incisor hypomineralization on oral healthrelated quality of life in schoolchildren," Brazilian Oral Research, vol. 30, no. 1, Article ID e117, 2016.

[13] P. D. Portella, B. L. V. Menoncin, J. F. Souza, J. V. N. B. Menezes, F. C. Fraiz, and L. R. d. S. Assunção, "Impact of molar incisor hypomineralization on quality of life in children with early mixed dentition: a hierarchical approach," International Journal of Paediatric Dentistry, vol. 29, no. 4, pp. 496-506, 2019.

[14] T. V. Gutiérrez, C. C. B. Ortega, N. P. Pérez, and A. G. Pérez, "Impact of molar incisor hypomineralization on oral healthrelated quality of life in Mexican schoolchildren," Journal of Clinical Pediatric Dentistry, vol. 43, no. 5, pp. 324-330, 2019.

[15] L. F. P. G. Tourino, P. Corrêa-Faria, R. C. Ferreira, C. B. Bendo, P. M. Zarzar, and M. P. Vale, "Association between molar incisor hypomineralization in schoolchildren and both prenatal and postnatal factors: a population-based study," PLoS One, vol. 11, no. 6, Article ID e0156332, 2016.

[16] L. Farias, I. C. C. Laureano, C. R. B. Alencar, and A. L. Cavalcanti, "Analysis of prevalence and diagnostic criteria of molar-incisor hipomineralization," Journal of Oral Research, vol. 8, pp. 254-262, 2019.

[17] J. L. F. Antunes, P. C. Narvai, and Z. J. Nugent, "Measuring inequalities in the distribution of dental caries," Community Dentistry and Oral Epidemiology, vol. 32, no. 1, pp. 41-48, 2004.

[18] Instituto Brasileiro de Geografia e Estatística, Panorama, 2017, https://cidades.ibge.gov.br/brasil/pb/campina-grande/.

[19] M. Malta, L. O. Cardoso, F. I. Bastos, M. M. F. Magnanini, and C. M. F. P. d. Silva, "Iniciativa STROBE: subsídios para a comunicação de estudos observacionais," Revista de Saúde Pública, vol. 44, no. 3, pp. 559-565, 2010.

[20] A. Ghanim, R. Mariño, and D. J. Manton, "Validity and reproducibility testing of the molar incisor hypomineralisation (MIH) index," International Journal of Paediatric Dentistry, vol. 29, no. 1, pp. 6-13, 2019.

[21] A. Ghanim, M. J. Silva, M. E. C. Elfrink et al., "Molar incisor hypomineralisation (MIH) training manual for clinical field surveys and practice," European Archives of Paediatric Dentistry, vol. 18, no. 4, pp. 225-242, 2017.

[22] N. Pitts, "ICDAS-an international system for caries detection and assessment being developed to facilitate caries epidemiology, research and appropriate clinical management," Community Dental Health, vol. 21, pp. 193-198, 2004.

[23] J. Jenny and N. C. Cons, "Establishing malocclusion severity levels on the Dental Aesthetic Index (DAI) scale," Australian Dental Journal, vol. 41, no. 1, pp. 43-46, 1996.

[24] Brasil. Ministério da Saúde. Secretaria de Vigilância em Saúde. SBBrasil 2010: Pesquisa Nacional de Saúde Bucal. Manual da Equipe de Campo. Brasília, , p. 53, Ministério da Saúde, 2009.

[25] D. Goursand, M. C. Ferreira, I. A. Pordeus, S. A. Mingoti, R. T. Veiga, and S. M. Paiva, "Development of a short form of the Brazilian Parental-Caregiver Perceptions Questionnaire using exploratory and confirmatory factor analysis," Quality of Life Research, vol. 22, no. 2, pp. 393-402, 2013.

[26] C. S. Torres, S. M. Paiva, M. P. Vale et al., "Psychometric properties of the Brazilian version of the Child Perceptions Questionnaire (CPQ11-14): short forms," Health and Quality of Life Outcomes, vol. 7, pp. 1-7, 2009.
[27] World Health Organization, Oral Health Surveys. Basic Methods, WHO, Geneva, Switzerland, 5th edition, 2013.

[28] K. Gambetta-Tessini, R. Mariño, A. Ghanim, H. Calache, and D. J. Manton, "The impact of MIH/HSPM on the carious lesion severity of schoolchildren from Talca, Chile," European Archives of Paediatric Dentistry, vol. 20, no. 5, pp. 417-423, 2019.

[29] E. Honkala, R. Runnel, S. Honkala et al., "Measuring dental caries in the mixed dentition by ICDAS," International Journal of Dentistry, vol. 2011, pp. 1-6, 2011.

[30] R. G. Oliven, "Cultura e Modernidade no Brasil," São Paulo em Perspectiva, vol. 15, no. 2, pp. 3-12, 2001.

[31] C. M. Fernandes, "Desigualdade de rendimentos e educação no Brasil: alguns indicadores de diferenças regionais," Econômica, vol. 3, pp. 231-250, 2001.

[32] R. Mariño, M. Morgan, and M. Hopcraft, "Transcultural dental training: addressing the oral health care needs of people from culturally diverse backgrounds," Community Dentistry and Oral Epidemiology, vol. 40, pp. 134-140, 2012.

[33] E. Wuollet, S. Laisi, S. Alaluusua, and J. Waltimo-Sirén, “The association between molar-incisor hypomineralization and dental caries with socioeconomic status as an explanatory variable in a group of Finnish children," International Journal of Environmental Research and Public Health, vol. 15, no. 7, pp. 1324-1334, 2018.

[34] M. O. Folayan, N. M. Chukwumah, B. O. Popoola et al., "Developmental defects of the enamel and its impact on the oral health quality of life of children resident in Southwest Nigeria," BMC Oral Health, vol. 18, pp. 160-170, 2018.

[35] A. V. D. Nóbrega, L. d. F. A. d. D. Moura, N. S. Andrade, C. C. B. Lima, D. G. Dourado, and M. d. D. M. d. Lima, "Impacto da cárie dentária na qualidade de vida de préescolares mensurado pelo questionário PedsQL," Ciência \& Saúde Coletiva, vol. 24, no. 11, pp. 4031-4042, 2019.

[36] R. C. Simões, M. L. Goettems, H. S. Schuch, D. D. Torriani, and F. F. Demarco, "Impact of malocclusion on oral healthrelated quality of life of 8-12 years old schoolchildren in Southern Brazil," Brazilian Dental Journal, vol. 28, no. 1, pp. 105-112, 2017.

[37] D. Bordin, C. B. Fadel, C. B. d. Santos, C. A. S. Garbin, S. A. S. Moimaz, and N. A. Saliba, "Determinants of oral selfcare in the Brazilian adult population: a national cross-sectional study," Brazilian Oral Research, vol. 31, Article ID e115, 2017.

[38] E. H. Sakly, W. B. Amor, N. Zokkar, C. Charavet, and F. B. Amor, "Prevalence of molar incisor hypomineralisation among school children aged 7-12 years in Tunis, Tunisia," Pesquisa Brasileira em Odontopediatria e Clínica Integrada, vol. 20, Article ID e0094, 2020.

[39] F. M. F. d. Silva, Y. Zhou, F. G. d. F. Vieira, F. M. d. Carvalho, M. d. C. Costa, and A. R. Vieira, "Defining the prevalence of molar incisor hypomineralization in Brazil," Pesquisa Brasileira em Odontopediatria e Clínica Integrada, vol. 20, Article ID e5146, 2020. 